Revista Iberoamericana, Vol. LXVIII, Núm. 200, Julio-Septiembre 2002, 753-763

\title{
JOSÉ MARÍA ARGUEDAS: ENTRE LA IDEOLOGÍA Y LA ARCADIA
}

POR

MARIo VARgas Llosa

Aunque los asuntos de mi país me importan mucho, y he dedicado la mayor parte de lo que he escrito al Perú, hasta donde yo puedo juzgar la literatura peruana ha tenido poca influencia sobre mis libros. Entre mis autores favoritos, esos que uno lee y relee y que llegan a constituir su familia espiritual, no figuran casi los escritores de mi propio país. Con una excepción: José María Arguedas. Es, entre los escritores peruanos, el único con el que he llegado a tener una relación verdaderamente pasional, como la que tengo con Flaubert o con Faulkner o la que tuve con Sartre. No creo que Arguedas fuera un gran escritor, como los que he mencionado, sino un buen escritor que escribió por lo menos una novela muy hermosa, lograda de principio a fin, Los ríos profundos, pero en cuyas otras obras, aunque sean éxitos sólo parciales, hay siempre elementos seductores y conmovedores. Creo que mi interés por José María Arguedas no se debe sólo a su obra sino, también, a su caso, privilegiado y patético. Privilegiado porque en un país escindido en dos mundos, dos lenguas, dos culturas, dos tradiciones históricas, a él le fue dado conocer a ambas realidades por igual, íntimamente, en sus miserias y en sus grandezas, y, por lo tanto, José María Arguedas tuvo una perspectiva muchísimo más amplia que la mía y que la de la mayor parte de los escritores peruanos sobre nuestro país. Patético porque el arraigo en esos dos mundos antagónicos hizo de él un desarraigado. Su vida fue triste, y traumas de infancia, que no llegó nunca a superar y que dejan una estela de temas y motivos en toda su obra, sumados a crisis de adulto al final, lo condujeron al suicidio. En el caso personal y en la obra de Arguedas se refleja el drama del escritor peruano y, seguramente, del latinoamericano: sus responsabilidades morales, sociales, políticas; también las presiones a que debe hacer frente, y cómo ellos inciden en su vocación literaria -a veces estimulándola y a veces destruyéndola. En José María Arguedas podemos estudiar de manera muy vívida la problemática del escritor latinoamericano, en general.

La novela de la cual voy a hablarles, Todas las sangres, publicada en 1964, es la más larga y la más ambiciosa que escribió, aunque tal vez sea la más frustrada de sus novelas. Pero una novela frustrada puede ser más instructiva y más elocuente sobre la visión del mundo de un escritor, sobre sus técnicas, sobre el sentido profundo de su arte, que una novela lograda. Todas las sangres es, en este sentido, una novela sumamente instructiva. El dijo, cuando publicó el libro, que hasta entonces su obra había ido creciendo espacialmente; que había comenzado escribiendo sobre una aldea, que su primer libro, una 
colección de cuentos llamada Agua, gira sobre la vida de un pueblecito, San Juan de Lucanas; que luego, en su segundo libro había descrito la vida de una provincia —y Yawar fiesta es una novela situada en el pueblo de Puquio; que luego había crecido hacia un departamento, que es el tema de Los ríos profundos, situado en el departamento de Abancay; y que, por fin, en Todas las sangres había conseguido su ambición: retratar en una novela toda la vida peruana. En realidad lo que retrata Toda las sangres es una de las grandes limitaciones de la literatura latinoamericana y peruana indigenista, algo que el propio José María Arguedas en sus mejores momentos logró superar: el ideologismo. Es una limitación que él había percibido cuando era todavía un escritor adolescente y había denunciado muy finamente en su primera novela, Yawar fiesta. Curiosamente, veinte años más tarde incurriría en ella.

El libro, sin embargo, al mismo tiempo que sucumbe a la tentación del ideologismo, internamente la contesta con una visión del mundo totalmente distinta a la ideología. Y esta contradicción, creo, da a la novela una tirantez que la hace fascinante, a pesar de sus defectos. Presenciamos en ella una lucha de dos fuerzas: una racional y otra irracional, que se disputan el mundo inventado, como se disputaron, en vida, la persona de José María Arguedas. Hay un elemento premeditado y un elemento espontáneo que comparecen en el libro y que son mutuamente inconciliables. La ambición de la novela está reflejada en el título: Todas las sangres. Es decir, todas las razas, todas las regiones, todas las culturas, todas las tradiciones, todas las clases sociales de ese gran mosaico que es el Perú. Efectivamente en Todas las sangres aparecen los Andes y la costa; los indios, los blancos y los mestizos; aparecen los ricos y los pobres, desde la cúspide de millonarios hasta la base campesina, con muchas divisiones y subdivisiones intermedias de esta pirámide social. Pero el propósito de la novela no sólo es cuantitativo; también cualitativo: mostrar que este mundo está signado por la injusticia y revelar los mecanismos de la desigualdad y del sufrimiento social en el Perú.

El esquema ideológico sobre el cual está construida la historia es muy simple y quiere ilustrar esta convicción: que la historia es una lucha de clases, de intereses inconciliables, en la que los poderosos someten a los débiles y los explotan o los destruyen, y en la que los débiles sólo pueden alcanzar su liberación destruyendo a los poderosos. El Perú aparece como un campo de batalla, de fuerzas irreconciliables, o como una pirámide de distintos segmentos en la cual los segmentos más minoritarios y más prósperos aplastan brutalmente a aquéllos en los que se apoyan y de los cuales se nutren. El vértice todopoderoso, quien tiene el máximo de la fuerza y del poder en esta sociedad, es una compañía imperialista, la Wisther and Bozart, que destruye a un capitalista nacional, don Fermín Aragón de Peralta, que ha descubierto una mina de plata en los Andes, la mina de San Pedro de Apark’ora. Esta es la primera oposición, contradicción o rivalidad que la novela quiere describir, la que existe entre el capitalismo imperialista y el capitalismo burgués nacional. La novela quiere mostrar gráficamente en esta lucha entre la Wisther and Bozart y don Fermín Aragón de Peralta cómo en la sociedad peruana el imperialismo impide que se desarrolle y prospere un capitalismo nacional y cómo el capitalista nacional está obligado a ser dependiente y a entrar en transacciones con el imperialismo.

A su vez, el capitalismo nacional, mediatizado por el imperialismo, ha prosperado gracias a una falta de escrúpulos y a una brutalidad semejante a la que ejerce el 
imperialismo contra él. Don Fermín Aragón de Peralta, para constituir su negocio minero, ha debido destruir a los agricultores de la región de San Pedro de Lahuaymarca, de cuyas tierras se ha apoderado, mediante fraudes y violencias, destruyendo prácticamente la agricultura que daba vida a la región. Esta es la segunda oposición que la novela quiere describir: minería versus agricultura, industria versus agricultura, capitalismo nacional versus feudalismo. Los señores feudales de la sierra de San Pedro de Apark'ora, de San Pedro Lahuaymarca, han sido empobrecidos cuando no destruídos por don Fermín Aragón de Peralta. El latifundismo es el sistema que ha imperado en la región desde la llegada de los conquistadores españoles en el siglo XVI. La novela retrocede hacia el pasado para mostrarnos cómo se constituyó el feudalismo andino, y cómo el feudalismo surgió también de la destrucción, el saqueo y el pillaje de las tierras de las comunidades indígenas, los distintos métodos por los cuales estas tierras fueron arrebatadas a los campesinos. El mundo feudal está dividido en distintos tipos humanos exactamente como el del capital nacional y el del imperialismo. Vemos, por ejemplo, que hay señores feudales que tienen un espíritu paternalista y benigno, como es el caso de don Bruno, el hermano de don Fermín, y que hay señores feudales primitivos y brutales, como es el caso de don Adalberto Cisneros, de don Lucas, y de otros gamonales explotadores verdaderamente implacables con sus siervos y sus campesinos.

Hay un esfuerzo en la novela, muy visible, para mostrar que esta estructura no es rígidamente esquemática, que hay en ella una cierta flexibilidad y que en estos segmentos se pueden encontrar distintos tipos de comportamiento, incluso distintas mentalidades éticas. Es decir, así como dentro de los feudales hay gentes, digamos, que tienen cierto carácter positivo, como don Bruno, en tanto que otros feudales son puramente negativos, en el mundo del capital, sea imperialista o nacional, hay, diríamos, buenos y malos, es decir, gentes capaces de tener cargos de conciencia, de percibir los horrores del sistema, y otros absolutamente impermeables contra todo género de escrúpulos.

Este esquema ideológico de la novela puede ser cierto, puede ser falso. No es lo que voy a discutir en esta ocasión. El mundo agrario que Arguedas describe a principios de los años 60 ya no es el del Perú de 1980. Algunas de las instituciones centrales en el libro hoy día han desaparecido, como el latifundio y el gamonalismo, después de la Reforma Agraria. Y tampoco creo que se pueda medir la verdad o la mentira de una ficción confrontándola con la realidad objetiva. La verdad y la mentira de una ficción están fundamentalmente determinadas por su poder de persuasión interno, por la capacidad que tiene de convencer al lector de aquello que cuenta, aún cuando esté — según la experiencia del lector- en contradicción flagrante con la realidad.

En la lectura de la novela, esta descripción esquemática de la realidad peruana la sentimos profundamente falsa, inconvincente, pero no tanto por su desadecuación a los hechos de la realidad como por su falta de poder de persuasión. Ocurre que este orden ideológico está en Todas las sangres contestado desde la propia novela por un orden paralelo que se ha filtrado y entreverado con aquél; se diría que impremeditadamente, sin que el autor lo quisiera y, acaso, sin que lo percibiera. Este otro orden no es, como el primero, racional sino irracional, un orden en el que no son los intereses económicos los que determinan esencialmente la marcha de la historia y en el que los hombres no son fundamentalmente entes históricos, sino metafísicos, que actúan de cierta manera no 
porque tengan intereses que defender dentro de la estructura social, sino porque tienen una esencia dada que los induce a actuar, diríamos, de manera fatídica en determinada dirección.

En el mundo de Todas las sangres un mal y un bien absolutos se reparten a las personas, a las instituciones, a las cosas, de una manera tan precisa que casi no hay en él campo para la ambigüedad. Todo es claro en ese mundo. Los malvados lo son no solamente para sus víctimas, los buenos, sino también para sí mismos. Tienen perfecta conciencia de su maldad y, al tiempo que la practican la declaran. No hay esfuerzo alguno en la novela para reconocer las razones del otro porque no hay razones contradictorias. Todos están de acuerdo en la clasificación moral de las conductas de las personas y de las instituciones. Así, por ejemplo, los imperialistas y los capitalistas que explotan, saquean, esquilman, engañan, roban, se confiesan ladrones, asesinos, destructores, etc. La injusticia no aparece en la novela —dentro de este orden- como en la visión ideológica, es decir, como el resultado de un mecanismo casi impersonal, determinado por las relaciones de producción, sino como consecuencia de cierta esencia, maldad o bondad congénita a los individuos. Los malos, por ejemplo, el Zar, que es el presidente de la compañía imperialista, don Fermín Aragón, el ingeniero Cabrejos, todo el grupo de servidores de estas instituciones, actúan con absoluta coherencia, una coherencia que es básicamente moral. Ninguno de ellos se busca jamás justificaciones o excusas. No existe eso que es tan frecuente, en la vida real, entre los burgueses y entre aquéllos que no lo son, es decir, el tener buena conciencia, el forjar coartadas morales para explicar la conducta. Los malos en la novela tienen una conciencia clarísima de su maldad, exactamente igual que los buenos. ¿Cuál es el resultado? El resultado es que ha desaparecido la ambigüedad, la complejidad humana, y que la novela nos recuerda un poco esas ficciones pre-cervantinas, ingenuas, candorosas, ejemplarizadoras, en las que el bien y el mal están repartidos de manera simétrica, en acciones, episodios y personajes. Igual que una novela primitiva, esto determina que la acción de Todas las sangres sea truculenta, llena de intrigas rocambolescas, y con muchos elementos grotescos. La novela primitiva partía del supuesto de que el tema era lo importante en una ficción. Sólo después descubrirán los novelistas que lo importante no es el tema sino el tratamiento del tema. Todas las sangres es una novela escrita bajo aquel supuesto, que lo importante es el tema, y que, entonces, el dramatismo, la energía, la fuerza narrativa, provienen de la naturaleza y contenido de la anécdota. Eso hace que la novela sea incandescente, desde el punto de vista anecdótico, que haya en ella tales dosis de violencia y de exageración que, en varios momentos, la disparan a la irrealidad.

La intriga es esencial en Todas las sangres. Quisiera darles algunos ejemplos. La rivalidad entre la compañía minera del capitalista nacional y la compañía minera imperialista genera intrigas paralelas que se cruzan y neutralizan. Por ejemplo, el jefe de correos de San Pedro de Lahuaymarca recibe simultáneamente sueldos de la compañía imperialista y de la compañía nacional para que ambas puedan leer recíprocamente sus cartas. Como la compañía imperialista paga más, el corrupto funcionario hace leer más cartas a esta compañía que las que hace leer a don Fermín Aragón de Peralta. Los recursos de que se valen los rivales para inutilizarse o destruirse son a veces, como dije antes, rocambolescos. Por ejemplo, para impedir que don Fermín Aragón llegue a la veta que está buscando en su mina, la compañía imperialista contrata a un mestizo a fin de que se 
introduzca secretamente en el socavón, en la noche, y en la mañana, cuando llegan los mineros a trabajar, ulule según el canto del Amaru —una serpiente mitológica-: esto aterrorizará a los mineros y los alejará del trabajo.

Hay un fenómeno interesante en la novela. Los malvados constituyen un linaje. Se reconocen unos a otros como por ósmosis, se hacen aliados instantáneamente apenas se ven y casi sin necesidad de palabras. Por ejemplo, hay un personaje, uno de los más terribles de la novela, el Suprefecto Llerena, que está a sueldo de la Wisther and Bozart. Al llegar a la sierra, le basta ver a don Adalberto Cisneros, que es la encarnación del malvado dentro del sector de los latifundistas, para que inmediatamente se establezca entre ellos una alianza. Recíprocamente, los buenos también establecen complicidades semejantes porque se identifican con sólo verse. Es como si esa bondad que emana de ellos estableciera una comunicación silenciosa apenas se encuentran. Por ejemplo, uno de los seres que representa el bien es un ingeniero limeño que ha trabajado para la compañía imperialista pero que al llegar a la sierra ha sido seducido, conquistado, tanto por el paisaje como por la humanidad de los Andes, y esto lo hace repudiar su condición anterior. Pues, basta que don Hidalgo Larrabure vea a Asunta de la Torre, una joven del pueblo de San Pedro de Lahuaymarca que representa la virtud y la pureza, para que inmediatamente entre los dos se establezca la misma inteligencia y solidaridad que entre Llerena y don Adalberto de Cisneros.

Igual que en una novela "naif”, en este mundo ocurren conversiones extraordinarias, para no decir milagrosas. Los malos pueden volverse súbitamente buenos cuando su corazón es tocado por alguna experiencia particular. Hay el caso de don Bruno. Don Bruno Aragón de Peralta, el hermano de don Fermín, es hasta la mitad de la novela, aproximadamente, un malvado. Ejercita la violencia contra sus trabajadores. En uno de los primeros episodios, lo vemos azotar públicamente a dos de sus mandones y a uno de ellos simplemente porque ha tenido una pequeña equivocación en el tratamiento al dirigirse a él. Vemos también que practica la violencia sexual como un deporte y que ha violado a multitud de mujeres en la región, incluso a un pequeño monstruo, a una jorobada enana, la Kurku Gertrudis. Pero, a la mitad de la novela, conoce a una mestiza llamada Vicente, que opera en él una verdadera transformación esencial, una transformación de tipo ontológico. A partir de ese momento, don Bruno comienza a practicar el bien con la misma consistencia, continuidad y terquedad con que hasta entonces practicaba el mal. Distribuye sus tierras entre los indígenas, ayuda a los comuneros libres de Paraybamba, al final entrega prácticamente todo lo que tiene a aquellos campesinos que ha expoliado y maltratado a lo largo de su vida. Y muere como un justiciero, ejecutando a dos gamonales crueles por las iniquidades que han cometido.

El propio don Fermín, ese capitalista nacional que durante gran parte de la historia también representa el mal absoluto, en un momento dado sufre asimismo una conversión. Sucede en el momento en que se vuelve, a su vez, víctima, víctima de la Wisther and Bozart. Ocurre en él algo más que una toma de conciencia: una transformación radical. Y ese hombre que ya es millonario, que ha alcanzado lo que era hasta entonces su ambición en la vida, bruscamente renuncia a todo eso y vuelve a la sierra decidido a modernizar la agricultura, a pagar altos salarios a los trabajadores, a importar ganadería fina. Al final de la historia don Fermín termina en el bando de los buenos. ¿Cómo no asociar esto a ciertas 
novelas medievales, por ejemplo la famosa Roberto el Diablo, que seguramente Uds. conocen? Roberto el Diablo, hijo del Duque de Normandía, el más cruel de los hombres de su tiempo, que gozaba acogotando a ancianas porque los ruidos que hacían al morir lo deleitaban, experimenta a la mitad de la novela, después de devastar Europa, una conversión milagrosa. El hombre más malo del mundo pasa a ser, a partir de entonces, el más bueno. Se pone a vivir como perro, literalmente a cuatro patas, y comer sólo las sobras que se echan a los animales. Así se redime. Es un esquema de maniqueísmo moral muy parecido, el de Todas las sangres.

El bien absoluto está representado en la novela por varios personajes pero, sobre todo, por uno, una especie de superhombre, que también hace recordar a las novelas medievales épicas, caballerescas, aquéllas centradas en torno a un justiciero extraordinario, como Amadís, como Tirante el Blanco, que es capaz de todas las proezas. Aquí, ese justiciero es un indio que se llama Rendón Willka. Ha nacido en una comunidad indígena en los Andes y ha pasado la prueba, esa prueba que pasaban los caballeros de la Edad Media antes de serlo, la prueba del infierno. El infierno ha sido bajar a la costa, ir a Lima. Ha vivido en las miserables barriadas, ha sido sirviente, vagabundo, ha pasado por la cárcel donde convivió con los delincuentes, y ahí tuvo una toma de conciencia político-religiosa (no digo ideológica sino político-religiosa), y ha vuelto a la sierra convertido en otro hombre, alguien decidido a luchar por la liberación de los indios, por los campesinos. Rendón Willka es, exactamente, un héroe de novela caballeresca. Es un hombre sereno en el que nunca hay rabia. Es sabio, paciente, lúcido, valiente, astuto, heroico, y, sobre todo, casto. Vamos a ver, después, que la castidad es una de las manifestaciones del bien en este mundo, así como la lujuria lo es del mal.

Una característica muy visible diferencia el bien del mal, los buenos de los malos, en la novela. Los malvados son siempre lógicos. Los malvados son siempre inteligentes, fríos, calculadores, cerebros que saben domesticar las emociones, que ponen los sentimientos siempre al servicio de sus fines intelectuales. En ellos no hay sentimentalismo, no hay jamás emotividad. La personificación de esto es el malvado absoluto de la novela, el presidente de la compañía imperialista, llamado el Zar. El Zar es un ser frío como un pescado. Es un hombre cuyo rostro jamás se inmuta, jamás expresa una emoción, que toma las decisiones - decisiones que a veces significan la extinción de un pueblo, la desaparición de una familia, la destrucción de una carrera - con una tranquilidad imperturbable, igual que una máquina. Esta psicología es típica de los malvados. Los buenos, en cambio, son siempre emotivos. Son sentimentales, predispuestos a llorar y a proceder por impulsos, sin previsión de las consecuencias de actos. Es el caso de los indios y en general, de los serranos. Un horror a la razón impregna el libro, y la creencia de que ella significa el mal, en tanto que el sentimiento, la emoción, expresan el bien.

Otras características diferencian, también, nítidamente a los buenos y a los malos. Los malvados son siempre corrompidos sexuales. Arguedas tenía una visión horrorizada del sexo. Su visión es, verdaderamente, la de un puritano, de tal manera que exagerando algo, pero muy poco, se puede decir que corrompido sexual en el mundo de Arguedas es todo aquel que hace el amor. Sus héroes son siempre castos. Rendón Willka es casto, y aquellos malvados que se vuelven buenos, inmediatamente dejan de hacer el amor. Es el caso de don Bruno. Ese ser lujurioso que ha desflorado a tantas muchachas de la región, desde el 
instante en que se convierte en bueno, se desexualiza. Y así, por ejemplo, vemos que besa a su mujer, a la mestiza Vicente, con una pureza extraordinaria, siempre en la frente. Los malvados suelen ser homosexuales. Hay una visión machista del sexo, que no es atributo sólo de Todas las sangres sino prácticamente de toda la obra de José María Arguedas, y probablemente, algo de lo que él no tuvo conciencia clara. Sus grandes malvados son homosexuales. Lo fueron en El Sexto, por ejemplo. Los rufianes de la prisión donde transcurre la novela, son todos pederastas. Lo es el malvado de su última novela, El zorro de arriba y el zorro de abajo, Brasqui, el industrial dueño de fábricas de harina de pescado. Y lo es en esta novela, por supuesto, el Zar, a quien vemos tratar de una manera equívoca, insinuante, a su principal colaborador, que tiene un apodo aterciopelado: Palalo.

La mujer, en la obra de Arguedas, aparece siempre idealizada hasta la irrealidad. Es la virgen, la madre, o, si no, el mal absoluto, es decir, la prostituta. Hay dos serranitas que pasan de manera fugaz por la novela y cuyo ejemplo es significativo. Son arrancadas de su comunidad por la miseria y precipitadas al infierno de Lima. Deben ganarse la vida primero como sirvientas y luego como obreras. Pero el drama que viven en Lima estas serranitas no es tanto el de la miseria, el de las privaciones, sino el de su castidad amenazada. Los patrones, en las casas donde trabajan como domésticas y luego en las fábricas, pretenden violarlas. Ellas luchan, defienden su doncellez, hasta que, en un momento dado, no tienen más remedio que sucumbir. Entonces, ambas se suicidan.

Como todo puritano horrorizado del sexo — ya sabemos que el amor y el odio se confunden - Arguedas era un hombre al mismo tiempo fascinado por él y por sus manifestaciones más barrocas. En esta novela eso ya es evidente, pero lo será todavía mucho más en la que escribirá después, El zorro de arriba y el zorro de abajo. Aquí tenemos muchos casos de esa sexualidad "pervertida" que, al mismo tiempo que lo atormentaba, indiscutiblemente lo atraía. Hemos visto el caso de don Bruno. Todavía peor es el del cholo Adalberto Cisneros, uno de los gamonales de la novela y, con el Zar, el personaje más negativo del libro. No sólo es cruel: también un terrible corrompido. Tiene accesos de rabia que lo llevan a torturar a sus peones, a colgarlos en las barras, a ponerlos en el potro y a azotarlos, y rabias que lo excitan, que provocan en él un afiebrado ardor sexual que aplaca, por supuesto, violando. Viola a todo lo que tiene pollera, a todo lo femenino que se pone en su delante. Viola a veces de dos en dos y no vacila en violar a una anciana que apenas puede andar como doña Adelina. A las mujeres que viola, además les prohibe llorar mientras son violadas, precisa la novela. Otro de los malvados prototípicos de Todas las sangres es un ingeniero, representante de la Wisther-Bozart, el ingeniero Velazco. Se trata, seguramente, de un fantasista sexual porque cada vez que un peón lo irrita, que un capataz no cumple sus instrucciones a la perfección, inmediatamente imagina un castigo para esta gente. ¿Y cuál es? Enviarlos a una prisión de Lima, el Sexto, y hacerlos violar con veinte negros.

Al mismo tiempo que los buenos son castos y los malvados, lujuriosos, hay otro rasgo que separa al bien y mal en la novela: los malvados suelen ser costeños y los buenos suelen ser serranos. Esto es el “andinismo”. Fue una de las características de la novela indigenista. Había una división topográfica del mal en esos libros. El bien y el mal estaban determinados geográficamente. En la obra de Arguedas esto todavía ocurre, a pesar de él mismo. Aunque él estaba muy consciente de que esto era un absurdo y racionalmente lo cambatía, cuando 
se ponía a escribir y se abandonaba a sus demonios, este tópico indigenista, el andinismo, aparecía. En Todas las sangres ello es evidente. Los peores malvados son siempre costeños en tanto que los grandes bondadosos son siempre serranos. La visión no es rígidamente esquemática, por supuesto. Entre los costeños puede haber buenos y entre los serranos puede haber malos. Pero el hecho de ser costeños y el hecho de ser serranos determina siempre un grado de maldad y de bondad diferentes. Así, por ejemplo, el ingeniero costeño y de buena familia, Hidalgo Larrabure, es bueno, pero es bueno porque es seducido por la sierra y, al mismo tiempo, su bondad jamás podrá alcanzar la estatura, la profundidad, la rotundidad, de la bondad de un serrano como Rendón Willka. Puede haber serranos malvados, como el cholo Adalberto de Cisneros que perpetra muchos crímenes, pero, por ser serrano, su maldad nunca llegará a ser tan absoluta, tan negra, tan total, como la del Zar, que, entre otras cosas, es costeño.

Además del andinismo, hay también en la novela el indigenismo entendido en términos raciales como elemento diferenciador del bien y del mal absolutos. Los malvados son blancos, generalmente, y los buenos son, generalmente, indios. La connotación racial es muy importante en la realidad ficticia. Pero, acaso, el peor de los malvados será siempre quien está a medio camino de los dos, el mestizo, como don Adalberto de Cisneros. Este “racismo al revés” fue una característica de la novela indigenista, a la que Arguedas, que escribió novelas más finas, más sutiles, más artísticas que las novelas indigenistas, sin embargo nunca pudo escapar del todo.

Una de las expresiones de la violencia en Todas las sangres es el número de suicidios. Yo he contado seis y quizás haya más. Se suicida el padre de los Aragón de Peralta, de don Fermín y don Bruno, en un episodio que es uno de los más hermosos del libro. La novela se abre con el viejo don Andrés trepando difícilmente el campanario de la iglesia de San Pedro de Lahuay-marca, para, desde esa torre, maldecir a sus hijos y dejar en herencia a los indios del pueblo todos sus bienes antes de suicidarse. Y a lo largo de toda la novela vamos viendo otras muertes por mano propia. Se suicidan indios como Policarpo Ledesma, se suicida un blanco empobrecido de San Pedro de Lahuay-marca al que apodan el Gálico. Se suicida Anto, el criado de don Andrés, volándose con un petardo de dinamita para pulverizar un bulldozer que quiere destruir su casa. Las mujeres de una comunidad indígena miserable, Paraybamba, matan a sus hijos recién nacidos porque saben que no van a tener qué darles que comer. Y, al final, vemos el suicidio de un pueblo entero, San Pedro de Lahuay-marca, cuando los vecinos descubren que la mina ha sido vendida a la compañía, que va a destruir enteramente la agricultura, que va a matar de sed a la región al edificar una represa exclusivamente para alimentar la mina, y deciden quemar el pueblo entero e irse todos. Queman la iglesia, queman sus casas y se van, se van a vivir a las barriadas de Lima como lumpens. El final de Todas las sangres propone una visión apocalíptica, dantesca, que, al mismo tiempo que aleja de la realidad objetiva a la novela, la acerca a una intimidad de Arguedas, que no es a esa conciencia racional que quiso imponer un esquema ideológico determinado a la descripción del mundo peruano, sino a algo muchísimo más complejo, espontáneo, profundo, y también auténtico que había en él.

Eso que había en él, creo, era una nostalgia desesperada por un mundo perdido, que se acababa, ya en gran parte destruido, y al que él en su fuero interno, en contra de sus 
convicciones, en contra de su razón, se sentía profundamente ligado. Este mundo es en parte arcaico, en parte utópico. Creo que el mejor Arguedas, el más admirable como creador, es el que describe ese mundo arcaico y utópico, que él sabía condenado y que secretamente -incluso secretamente para él mismo — defendía con pasión y talento. En ésta, como en su mejor novela, Los ríos profundos, y como en todas las novelas que escribió, este mundo arcaico aparece injertado, filtrado, dentro de ese otro mundo, ideológico, racional, deliberado, y es para mí el que origina sus mejores páginas y, también, sus mejores personajes. Este mundo está incontaminado de modernidad, alejado de la costa y de todo lo que es extranjero. Es un mundo que Arguedas llamaba "peruano". Su idea de lo "peruano" es inseparable de lo serrano y de lo antiguo. Un mundo no corrompido, virginal, casto, mágico, ritual, que hunde sus raíces en el pasado peruano. Un mundo que se ha preservado de manera casi milagrosa, gracias al espíritu de resistencia de los indios contra las invasiones, presiones y expoliaciones de que ha sido objeto. Este mundo es, por supuesto, rural y es, también, musical: un mundo donde los seres se expresan mejor cantando que hablando. Como en las otras novelas de Arguedas, aquí también el canto es importantísimo. Quizás las páginas más tiernas son aquéllas donde los personajes no hablan, piensan, actúan, sino cantan.

El canto no es sólo una manifestación de dolor o de felicidad, es un lenguaje que comunica a los hombres con la naturaleza, una naturaleza recónditamente animada. Una naturaleza en la que las montañas, los cerros tutelares, tienen almas, nombres, y se manifiestan a los hombres de distintas maneras. Una de esas maneras es a través de las aves. Hay gavilanes que aparecen, por ejemplo, cuando los alcaldes indios convocan a cabildo. Ellos saben interpretar por el vuelo de los gavilanes o por las motas que colorean las alas de estos pájaros, si los signos son favorables o desfavorables. Incluso los blancos de la sierra, que consideran esto brujería, superchería, superstición, son sensibles a la existencia de estos seres maravillosos en el seno de las montañas y, así, vemos que el capitalista nacional, don Fermín Aragón de Peralta, durante un viaje, al cruzar el abra de una montaña, deposita una pequeña ofrenda para convocar el favor del espíritu del lugar.

Este mundo, aparte de musical, es ritual, ceremonioso. Todas las sangres está llena de ritos, ceremonias que no son las prototípicas (los entierros, las procesiones) sino actividades cotidianas que adoptan un carácter ceremonial. Esto ocurre, fatídicamente, cuando los personajes son indios. Los trabajos en la comunidad son ceremonias puntillosamente prescritas; las simples conversaciones, la manera cómo los inferiores se dirigen a los superiores, los jóvenes a los ancianos, los hombres a las mujeres, repiten costumbres que vienen de muy atrás y el hecho que la respeten o la influyan determina, justamente, que los hombres de este mundo sean de signo positivo o de signo negativo.

Así como las piedras y los cerros tienen un alma, una vida, también la tiene la flora. Los árboles son personajes siempre importantes en los cuentos y las novelas de Arguedas. En una de sus novelas, acaso el personaje más vívido y conmovedor sea un árbol: El zorro de arriba y el zorro de abajo, donde hay un pino, en la ciudad de Arequipa, un pino altísimo, con el que el narrador celebra en un momento determinado un diálogo extraordinariamente tierno, y la descripción de ese pino arequipeño es una de las mejores cosas que José María Arguedas escribió. El árbol es en su mundo, un ser lleno de vida y con características humanas. En uno de sus cuentos, por ejemplo, hay un árbol hembra; 
en otro, hay un árbol afeminado. Aquí hay un árbol maravilloso, un pisonay que está en la casa de don Bruno Aragón de Peralta, el latifundista bueno, y al que vemos registrar como un barómetro ciertos episodios que ocurren a su alrededor. Así, cuando don Bruno parte, al final de la historia, como justiciero, decidido a matar a dos gamonales para castigarlos por sus maldades, vemos que el pisonay se encoge y que sus flores, que son rojas, bruscamente se apagan. Y don Bruno —en esto un indio- sabe interpretar los signos: no volverá de este viaje. En cambio, unas páginas después, cuando Rendón Willka exorta a los indios a resistir a las tropas del gobierno que vienen a reprimirlos y oímos a los indios gritar que así lo harán, vemos cómo el pisonay —lo dice textualmente el narrador- crece y sus flores se ponen muchísimo más rojas.

Los ríos son también seres animados. Los ríos hablan. El rumor del agua al correr sobre las piedras dice cosas, contiene mensajes que los indios saben interpretar y, por ejemplo, los músicos recogen, ciertas noches del año, del canto de las aguas con la creciente, ciertas notas que verterán más tarde en sus instrumentos. Todo esto no está distanciado del sentimiento y la palabra del narrador y del autor en las novelas de Arguedas. Arguedas sentía tan profundamente esto como sus personajes y para él eso constituía lo mejor del país, aquello que había dado al Perú una personalidad propia, distinta, intransferible.

En una de sus novelas, en El Sexto, uno de sus personajes, personaje “positivo”, dice que lo que nunca podrá perdonarle al Perú blanco, al Perú de la costa, es haber desoído la voz del pasado, haber olvidado que el Perú es un país antiguo. La “antigüedad” en la obra de Arguedas es un valor y, quizás, el primer valor. Son aquéllos que tienen sentido de lo antiguo, que respetan la tradición y la costumbre, los que representan siempre lo positivo, como Rendón Willka o como don Bruno. Otro personaje positivo del libro, la señora Matilde, le dice a don Fermín, cuando se despide de él, que va a viajar a la costa: "Mantente antiguo": Y a este ideal antiguo se convierte el joven Hidalgo Larrabure en la sierra. Esto es lo que lo purifica y, dice la novela, lo peruaniza. Hay un diálogo entre este joven, ganado por el bien, ganado por la sierra, ganado por el andinismo, y don Fermín Aragón de Peralta, que es bastante significativo. Dice don Fermín: "Bruno quiere una república de indios manejada por señores caritativos”. "Yo, también, señor de Peralta”, dice Hidalgo Larrabure, "una república de indios en el sentido de no destruir lo que tenemos de antiguo, de no destruirlo sino desarrollarlo”. La contrapartida de esta adhesión a lo antiguo como valor es el rechazo del progreso tecnológico. Arguedas intuía, y creo que de manera muy correcta, que el progreso tecnológico, el progreso industrial, era simplemente incompatible con este ideal arcaico. No hay mundo campesino, mágico, religioso, folklórico, que sobreviva al desarrollo industrial. No importa de qué signo sea el desarrollo industrial, capitalista o socialista. Y por eso, en la obra de Arguedas, hay un rechazo (visceral, irracional, pero clarísimo) del progreso, de la idea misma de progreso.

Esto es algo que él comprendía y que racionalmente le parecía inaceptable. Pero irracionalmente no podía desprenderse de él. Me parece que ésta es una de las contradicciones que da justamente a sus últimas novelas —a Todas las sangres y a El zorro de arriba y el zorro de abajo - una tirantez y un dramatismo particular. Aquí vemos, aunque no de manera tan rotunda como en la novela posterior, ese rechazo del progreso. La mina —es decir, la tecnología, la industria — está presentada con caracteres verdaderamente diabólicos. 
La mina destruye el paisaje de la sierra, mata la agricultura, asesina culturalmente al mundo quechua, y vuelve a los campesinos obreros asalariados. Los priva de su lenguaje, los priva del quechua, los hace hablar como robots. La mina también es un factor de corrupción, envilece a las mujeres y aparece en la sierra la prostitución. Un detalle muy ingenuo y muy conmovedor es que los indios son corrompidos por la mina porque la mina trae prostitutas, prostitutas que enseñan a los indios “suciedades” a la hora de hacer el amor. (Muy ingenuo porque si Uds. han visto los huacos eróticos peruanos descubren que los indios sabían de "suciedades" eróticas todo, mucho antes de que llegaran los españoles.) Pero en la representación utópica de Arguedas, el mundo indio es casto, virginal.

La llegada de las máquinas a la sierra está presentada como la llegada del mal. Los bulldozers van destruyendo las cabañas indias y uno de los personajes más puros de la novela, el sirviente Anto, se suicida tratando de destruir un bulldozer. El narrador termina ese episodio con esta frase: "Los monstruos habían triunfado".

Curiosamente, en una novela escrita con el deliberado propósito de interpretar a la sociedad peruana en función de una ideología progresista, de describir la historia del Perú en función de la lucha de clases, lo que acaba por imponerse en este libro, como en otros de Arguedas, es una utopía arcaica. La idea del pasado como valor. La patria como un imperativo moral. El amor a los ritos, a las jerarquías, a las ceremonias, que es algo que caracteriza a las sociedades tradicionales, y un horror instintivo, religioso, a la modernidad, a toda forma de progreso industrial y tecnológico, porque ello acarrearía consigo la desaparición de lo antiguo y traería consigo males superiores a aquéllos que vendría a remediar.

Un escritor nunca sabe para quién trabaja, si trabaja con la totalidad de su ser, con su razón y con su sinrazón, con sus ideas y con sus obsesiones, con sus intuiciones y con sus instintos. Arguedas era, en este sentido, un auténtico escritor, un hombre que creaba con toda su personalidad y con todas sus contradicciones. Y eso es lo que hizo posible esta paradoja: que una novela escrita tan deliberadamente con la intención de ser —y no sólo parecer - un progresista, un hombre comprometido con la revolución socialista, resultara, en realidad, una novela profundamente conservadora.

Volumen XLVII

Julio-Diciembre 1981

Números 116-117 